\author{
Wouter L. Lodder \\ Hendrik J. Teertstra \\ Ing B. Tan \\ Frank A. Pameijer
}

Ludi E. Smeele

Marie-Louise F. van Velthuysen

Michiel W. M. van den Brekel

\section{Tumour thickness in oral cancer using an intra-oral ultrasound probe}

Received: 3 May 2010

Revised: 8 June 2010

Accepted: 20 June 2010

Published online: 3 August 2010

C The Author(s) 2010.

This article is published with open access at Springerlink.com

W. L. Lodder I. B. Tan • L. E. Smeele

M. W. M. van den Brekel (

Department of Head \& Neck Surgery and Oncology,

Netherlands Cancer Institute-Antoni van

Leeuwenhoek Hospital,

Plesmanlaan 121, 1066 CX Amsterdam,

The Netherlands

e-mail: m.vd.brekel@nki.nl

Tel.: +31-20-5122550

Fax: +31-20-5122554

\section{H. J. Teertstra}

Department of Radiology,

Netherlands Cancer Institute-Antoni van

Leeuwenhoek Hospital, Amsterdam,

The Netherlands

I. B. Tan · M. W. M. van den Brekel Department of Otorhinolaryngology, Academic Medical Centre,

University of Amsterdam, Amsterdam,

The Netherlands

\section{F. A. Pameijer}

Department of Radiology,

University Medical Centre Utrecht, Utrecht,

The Netherlands

M.-L. F. van Velthuysen

Department of Pathology,

Netherlands Cancer Institute-Antoni van

Leeuwenhoek Hospital, Amsterdam,

The Netherlands
Abstract Objectives To investigate tumour-thickness measurement with an intra-operative ultrasound (US) probe. Methods A retrospective data analysis was undertaken for a total of 65 patients with a T1-2 oral cavity cancer, who were seen at a tertiary referral centre between 2004 and 2010. The correspondence between tumour thickness measured by ultra- sonography and histopathology was assessed by Pearson's correlation coefficient, and also between tumour thickness and the development of neck metastasis. Results In 11 cases, intra-oral measurement was not opti- mal due to limited mouth opening $(n=2)$ or impossibility to depict

the lesion $(n=9)$. Tumour thickness measured by US correlated well with histopathology ( $n=23, R=0.93)$. Tumour thickness of $\leq 7 \mathrm{~mm}$ carries a risk of lymph node metastasis of $12 \%$, whereas in tumours exceeding $7 \mathrm{~mm}$ this risk is $57 \%(p=0.001)$. Twenty-five percent developed neck metastasis and 19\% had local recurrence. Conclusion Tumour thickness is an important predictive marker for lymph node metastases. As such, it can help in decision-making with regard to management of the primary tumour and neck. Based upon our findings, a wait-and-see policy is only warranted for superficial lesions with tumour thickness of less than $7 \mathrm{~mm}$, but only if regular follow-up using US-guided aspiration of the neck is ensured.

Keywords Intra-oral ultrasonography - Tumour thickness . Head and neck - Cervical metastasis . MR imaging

\section{Introduction}

Predicting the risk of lymph node metastases in clinically N0 patients with oral cancer is very important in treatment planning for the neck. Tumour thickness has been shown to be one of the most important features in predicting lymph node metastases in oral cancer. Since 1986 several studies have focused on tumour thickness [1-3]. In 2005, Pentenero et al. [4] showed in a large review cut-off points as prognostic factors ranging from $2 \mathrm{~mm}$ to $10 \mathrm{~mm}$. Table 1 shows cut-off values for all studies used in this article and studies performed after the review of Pentenero et al. [4]. Tumour thickness is not the only important 
Table 1 Reviewed articles: from 1986 to 2009, displayed with number of patients, TNM stage, studied site, and cut-off values found by ultrasound for N0 versus pathological N+ (FOM floor of mouth, $N+$ tumour thickness significant for nodal involvement)

\begin{tabular}{llllll}
\hline Reviewed articles & Year & Number patients & TNM & Site & S + \\
\hline Spiro et al. [1] & 1986 & 92 & Any TN & Oral cavity & $2 \mathrm{~mm}$ \\
Mohit et al. [14] & 1986 & 84 & T1-2N0 & FOM & $1.5 \mathrm{~mm}$ \\
Rasgon et al. [3] & 1988 & 22 & Any TN & Oral cavity & $5 \mathrm{~mm}$ \\
Woolgar et al. [15] & 1995 & 50 & T2 & Tongue & $8 \mathrm{~mm}$ \\
Martinez et al. [16] & 1995 & 126 & Any TN & Oral cavity & $7 \mathrm{~mm}$ \\
Fukano et al. [13] & 1996 & 34 & Any TN & Tongue & $5 \mathrm{~mm}$ \\
Shintani et al. [10] & 1997 & 53 & Any TN & Oral cavity & $8 \mathrm{~mm}$ \\
Byers et al. [17] & 1998 & 91 & Any TN & Tongue & $4 \mathrm{~mm}$ \\
Scheer et al. [18] & 2005 & 64 & Any TN & Oral cavity & $13 \mathrm{~mm}$ \\
Veness et al. [19] & 2005 & 99 & Any TN & Tongue & $5 \mathrm{~mm}$ \\
Jing et al. [20] & 2006 & 45 & Any TN & Oral cavity & $5.2 \mathrm{~mm}$ \\
Clark et al. [21] & 2006 & 105 & Any TN & Oral cavity & $5 \mathrm{~mm}$ \\
Wallwork et al. [22] & 2007 & 53 & Any TN & FOM & - \\
Suzuki et al. [23] & 2007 & 48 & T1-2N0 & FOM & - \\
Okura et al. [24] & 2008 & 43 & Any TN & Tongue & $5 \mathrm{~mm}$ \\
Kim et al. [25] & 2008 & 82 & Any TN & Oral cavity & $8.7 \mathrm{~mm}$ \\
El-Okeily et al. [26] & 2008 & 124 & T1-3N0 & Oral cavity & - \\
Natori et al. [27] & 2008 & 110 & Any TN & Tongue & - \\
Huang et al. [2] & 2009 & 1,136 & Any TN & Oral cavity & $8 \mathrm{~mm}$ \\
\hline
\end{tabular}

predictive factor; other important characteristics of the tumour are: epidemiologic parameters such as age, sex, race, alcohol, and/or tobacco intake, clinical parameters (TNM stage, site) and histopathological parameters such as the tumour border, being either infiltrative or more pushing, perineural invasion and vascular invasion [4-6]. Recently, it has also been shown that gene expression of the primary tumour correlates with the risk of cervical metastases [7].

Separate from predicting the development of lymph node metastases, the measurement of tumour thickness may have implications for the treatment of the primary tumour as well. Limited oral cancer in general is treated surgically, using postoperative radiotherapy or chemoradiation in the case of unfavourable histopathological features. In superficial oral cancer, apart from local excision, $\mathrm{CO}_{2}$ laser resections and photodynamic therapy (PDT) have also been shown to yield excellent results [8].

However, the results of these alternative treatments are very much dependent on the amount of tumour infiltration (i.e. tumour thickness). Although depth of infiltration is predictive for the chance of local recurrence as well [6], it is not routinely used as an indication for postoperative radiotherapy in most clinics. A recent study showed that tumour thickness is also predictive for the risk of contralateral cervical metastasis in tongue carcinoma [9].

To measure tumour thickness, different techniques are available. Several studies have compared intra-oral ultrasound (US) with magnetic resonance imaging (MRI) or computed tomography (CT) $[10,11]$. In 1989, Iro and Nitsche [12] showed that using a miniaturised transducer enables the depiction of tumours of the anterior tongue and the floor of the mouth without artefacts. They found this method to be superior to conventional US for this region.

Since June 2007 we have been using a new intraoperative transducer (Philips IU-22 L 15-7; 7-15 MHz). In this study, we present our results with respect to the feasibility of US measurement of intra-oral tumour thick- ness, correlation with the presence of lymph node metastases as well as correlation with MRI, with histopathology as the "gold standard".

\section{Patients and methods}

Ethical considerations

This was a retrospective study with anonymous evaluation of data; therefore, written informed consent was not required.

\section{Selection criteria}

All patients with stage $\mathrm{T} 1-\mathrm{T} 2$ oral cancer planned for transoral excision or photodynamic therapy (PDT) in our department were included $(n=65)$. All patients were seen between 2004 and 2010.

\section{Participants}

Ages ranged from 42 to 89 years (mean 65 years) and the sex ratio was 34 men to 31 women. The cancers were localised in the tongue $(n=38)$, the floor of the mouth $(n=$ 22 ) and elsewhere in the mouth $(n=5)$.

Clinical T-stages of the 65 patients were as follows: T1 $(n=50), \mathrm{T} 2(n=15)$; N-stages were: N0 $(n=59), \mathrm{N} 1 \quad(n=4)$ and $\mathrm{N} 2(n=2)$.

Intra-oral US was used in all 65 patients, and MRI was performed in 36 cases. MRI was only performed as part of the preoperative treatment planning, in patients possibly applicable for transoral excision. In 13 cases the lesion was not found on MRI, because of superficial growth. These lesions were interpreted as minimal lesions of less than 1-mm thick. 
Patients underwent transoral excision $(n=30), \mathrm{CO}_{2}$ laser excision $(n=3)$ or photodynamic therapy (PDT) $(n=29)$, or a combination of surgery with postoperative radiotherapy $(n=$ $3)$. Within the group of patients treated with PDT $(n=29)$ the localisations were as follows: 13 tumours of the tongue, 13 in the floor of the mouth and three elsewhere in the mouth.

Twelve patients underwent a primary neck dissection.

Histopathological data on thickness were available in all 33 surgically treated patients.

Current treatment protocol

US measurement of tumour thickness is currently used to select patients treatable with PDT. In tumours of less than 5 -mm thick, PDT treatment can be used as light penetration up to $1 \mathrm{~cm}$. We chose PDT especially in cases where surgery carried a risk of Warthin's duct obstruction or a marginal mandibulectomy. For thicker tumours, we always perform a local excision. The neck is staged using US-guided aspiration cytology (USgFNAC) and a sentinel node procedure in the case of a negative USgFNAC and treatment of the primary with transoral excision. For negative sentinel nodes, a wait-and-see policy is the standard. In the case of positive sentinel nodes or a positive USgFNAC, a neck dissection is carried out.

\section{Measurement of tumour thickness}

For US measurement of tumour thickness, an intraoperative transducer (Philips IU-22, L15-7; 7-15 MHz) was used $(n=44)$. Before June 2007, a small parts transducer probe $(5-7 \mathrm{MHz})$ was used in 21 patients. Tumour thickness was measured by placing the probe directly on the lesion. The same radiologist performed all intra-oral measurements on the outpatient clinic, 1 or 2 weeks before surgery without anaesthesia.

Using an US probe or MRI, the thickness of the tumour is measured and not the depth of infiltration from an imaginary line at the level of the mucosal surface. So, in this study we measured maximal tumour thickness also with histopathological sections, and not the depth of infiltration.

On histological sections, the tumour thickness was measured using the ocular micrometer. MRI examinations were performed at 3.0 T (Philips Achieva release 3.2.1, Philips Medical Systems, Best, The Netherlands) using a dedicated 16-channel SENSE neurovascular coil.

The following series were acquired: STIR TSE COR, TR (repetition time), IR (inversion time), TE (echo time) $3,880 / 180 / 20 \mathrm{~ms}$, ETL: 12, FOV 300/228/40 mm, matrix: 320/320, 2 nex, slice thickness $4 \mathrm{~mm}$; STIR TSE TRA, TR/IR/TE 4,228/180/20, ETL: 12, FOV: 180/200/80 mm, matrix 300/312, 2 nex, SW $3.5 \mathrm{~mm}$, T1 TSE TRA, TR/ TE: 780/10, ETL: 5, FOV 180/180/80, matrix 384/384, 2 nex, slice thickness: $3.5 \mathrm{~mm}$; T1 3D Thrive [performed after intravenous injection of $15 \mathrm{cc}$ gadoterate meglumine (Dotarem)], TR/TE: 5/2,22, ETL:90, TA: 10, FOV 230/ 272/220, matrix 288/288, 2 nex, slice thickness: $0.8 \mathrm{~mm}$;
T1 TSE COR (post contrast): TR/TE: 812/10, ETL: 6, FOV: 180/150/96 mm, matrix: 320/320, 3 nex, slice thickness $3.5 \mathrm{~mm}$.

The US findings of the patients treated with PDT and $\mathrm{CO}_{2}$ laser could not be correlated with histopathological measurements, for obvious reasons. Figure 1 shows the measurement of a tumour using the three techniques.

Statistical analysis

The correlation between tumour thickness as measured by US, MRI and in the histopathological sections was evaluated. Pearson's product correlation analysis was performed on all data in order to determine the overall correlation between them. The correlation between tumour thickness and the presence of lymph node metastases was analysed using the chi-squared test.

\section{Results}

Tumour thickness

For all 65 patients, US measurement of the oral lesion was obtained. For 11 cases, intra-oral measurement was not optimal due to limited mouth opening $(n=2)$ or the impossibility of depicting the lesion $(n=9)$. There was no difference between the old and the new transducer probe (four versus seven cases). Tumour thickness ranged from $1 \mathrm{~mm}$ to $35 \mathrm{~mm}$, with an average of $8 \mathrm{~mm}$.

MRI was performed on 36 patients. Tumour thickness ranged from $1 \mathrm{~mm}$ to $24 \mathrm{~mm}$, with an average of $5 \mathrm{~mm}$.

On histopathology $(n=33)$, tumour thickness ranged from $1 \mathrm{~mm}$ to $35 \mathrm{~mm}$ with an average of $8 \mathrm{~mm}$.

\section{Correlation with histopathology}

Correlation between US and histopathology could be made in 31 cases. For two surgically treated patients, US could not be performed. Correlation between MRI and histopathology could be made in 22 cases. Pearson's product correlation (Figs. 2, 3) between US and MRI imaging was significantly different. With a correlation product of $R=0.87$, US correlated better with histopathology than MRI $(R=0.54)$. Comparing the old transducer used before 2007 and the new intra-oral probe, the Pearson's product was respectively 0.05 versus 0.93 (Fig. 4)

\section{Neck node metastases}

In total, 12 patients $(\mathrm{N} 0=6, \mathrm{~N} 1=4, \mathrm{~N} 2=2)$ initially underwent 12 neck dissections, six therapeutic and six elective. Of these 12 neck dissections, nine were pathological $\mathrm{N}+(\mathrm{pN}+)$. In total, 53 clinically $\mathrm{N} 0$ patients did 

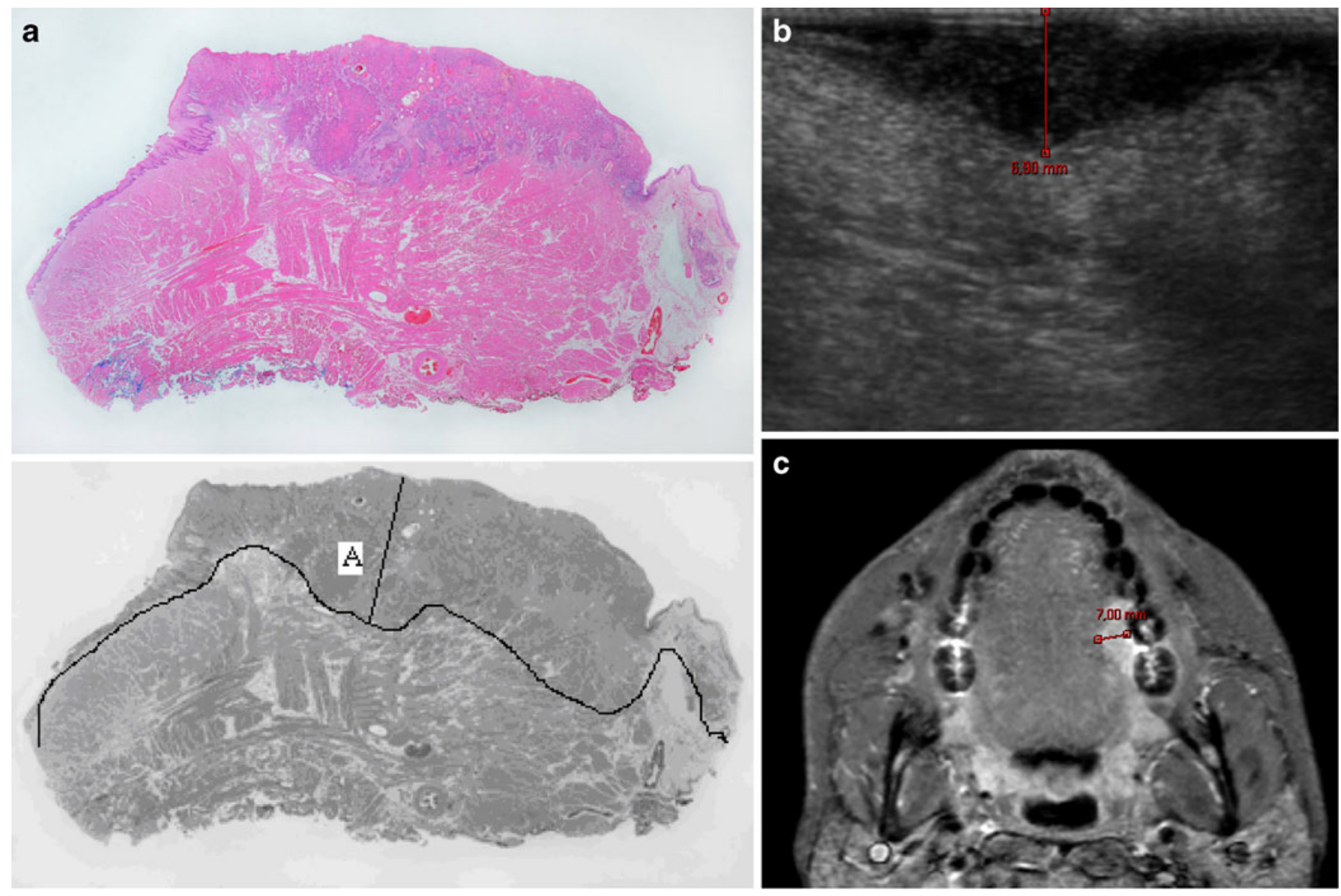

Fig. 1 Tumour thickness on histology, US and MRI. a Histological section showing a tumour of the tongue. Tumour thickness is 8 mm ( $A$ indicates diameter). b US picture of the same tumour of the tongue. c Tumour thickness measured on MRI

not undergo a neck dissection initially. During follow-up, seven patients in this wait-and-see group developed a neck node metastasis. Of these seven patients, three also had local recurrence. Thus, a total of 16 of the $65(25 \%)$ patients were $\mathrm{pN}+$. Of these 16 patients, US could be performed in 13 cases.

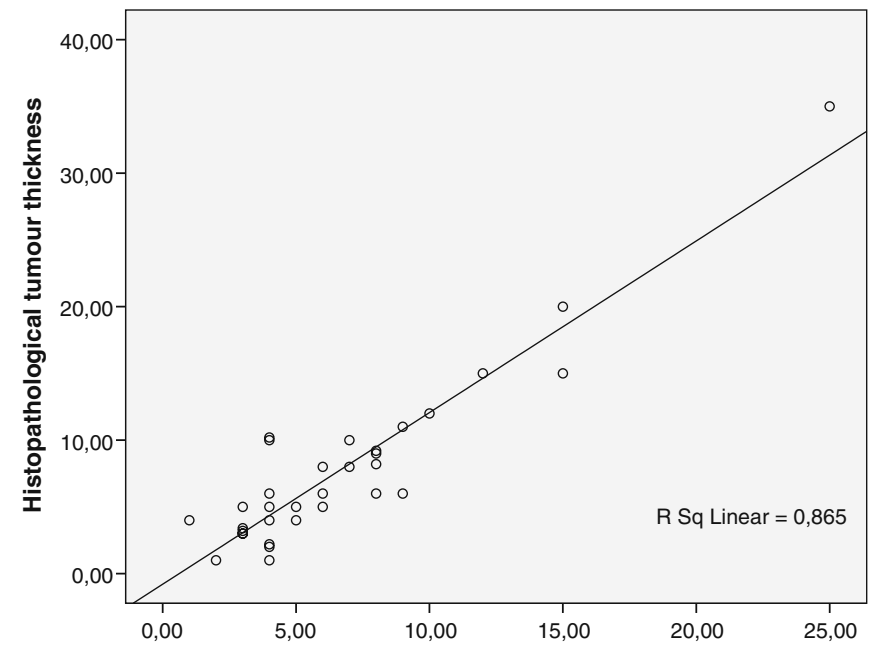

Fig. 2 Correlation between tumour thickness on histological section and by US; $n=32$, Pearson's product $R=0.87$
Correlation of tumour thickness and lymph node involvement

In the patients with available histopathological measurement, histopathologically measured tumour thickness was used to correlate with lymph node metastasis. For

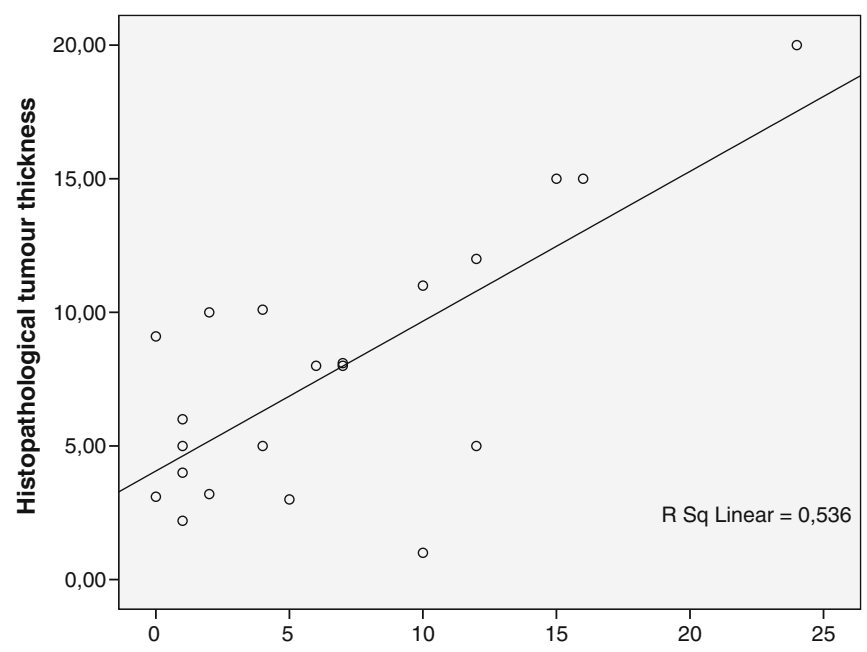

Fig. 3 Correlation between tumour thickness on histological section and by MRI; $n=22$, Pearson's product $R=0.54$ 


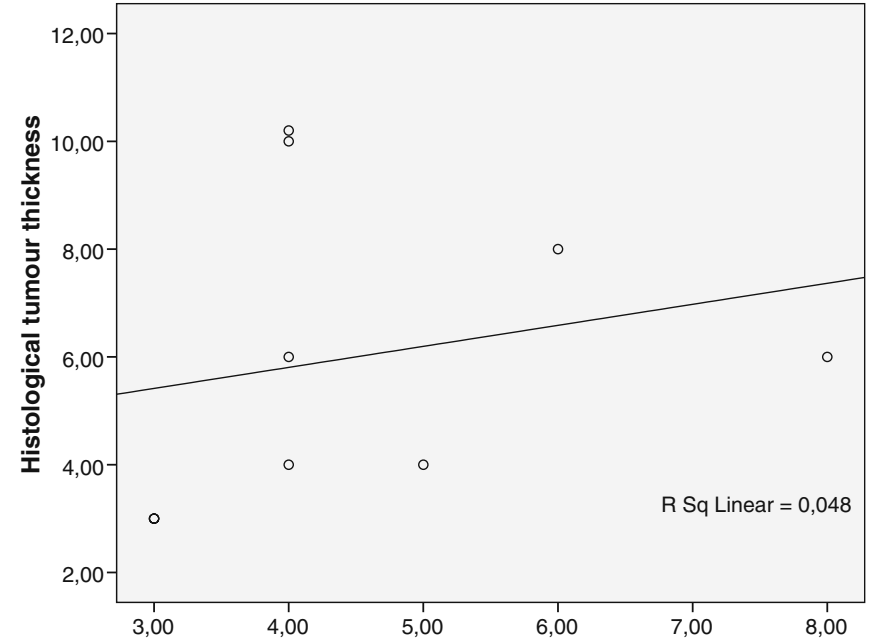

Philips Small parts transducer 5-7 MHz (N=9) IU-22 R=0,05

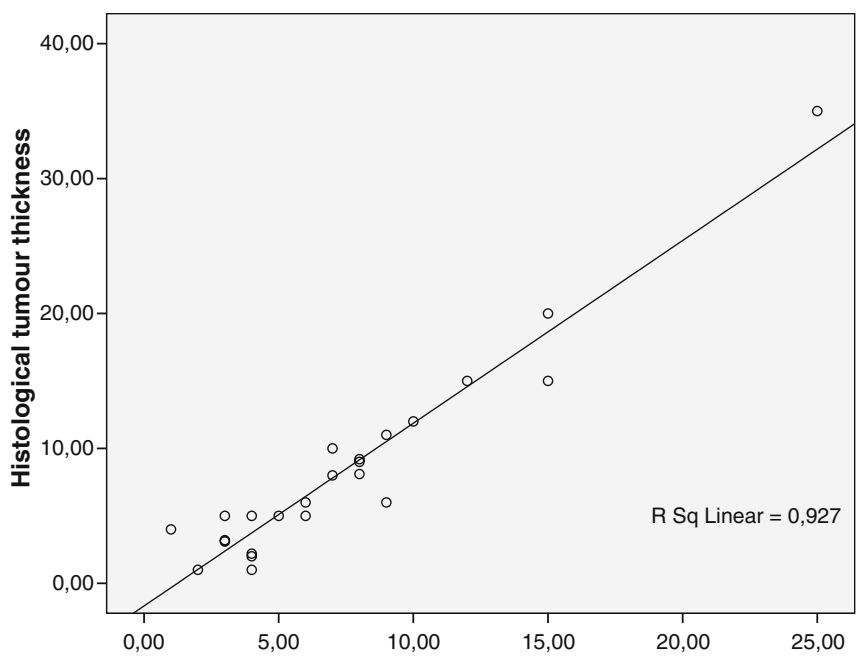

Intra operative transducer, Philips L15-7; 7-15 MHz (N=23) $\mathrm{R}=0,93$

Fig. 4 Correlation between tumour thickness on histological section and by US. Sub-selection between a Philips small-parts transducer probe $(5-7 \mathrm{MHz})$ and the intraoperative transducer probe, Philips IU-22)

the 32 cases in which histopathology was not possible, the US-measured thickness was used (only measured with the new intra-oral transducer probe). Therefore in total, correlation was possible in 56 patients (Fig. 5). One metastasis $(1 / 20=5 \%)$ was found in patients with a histological tumour thickness of $3 \mathrm{~mm}$ or less. Four patients had cervical metastasis with tumour thickness between 4 and $7 \mathrm{~mm}(4 / 22=18 \%)$. When the tumour thickness exceeded $7 \mathrm{~mm}$, the cervical metastases rate increased to $57 \%(8 / 14)$. The difference in metastasis for 7-mm tumour thickness was significant at $p=0.001$. Table 2 shows sensitivity and specificity by cut-off value.

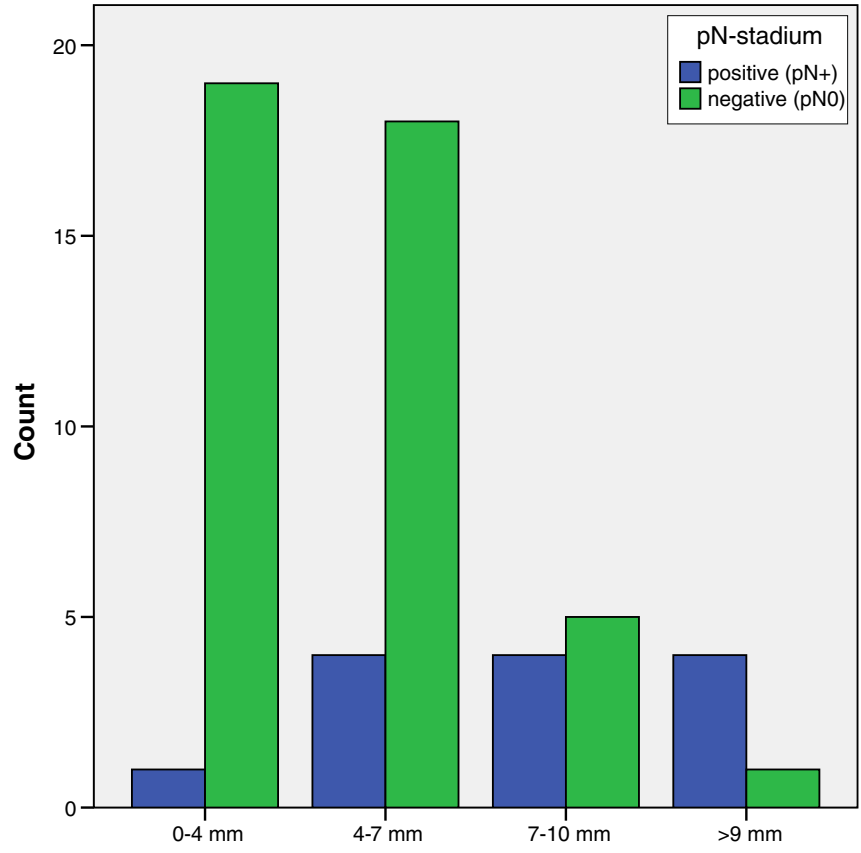

Fig. 5 Relationship between tumour thickness and cervical metastases $(n=56)$. Tumour thickness measured by intra-oral US probe, if not available measured by histopathology $N=56$. Green represents the patients with no neck metastasis within the 2-year follow-up period; blue represents the patients with positive neck nodes during the follow-up period

Correlation of tumour thickness and lymph node involvement by site

Within the group of tongue carcinomas $(n=36)$, none of the patients had cervical metastasis with histological tumour thickness of $3 \mathrm{~mm}$ or less (Fig. 6). Three patients had cervical metastasis with tumour thickness between 4 and $7 \mathrm{~mm}(3 / 18=17 \%)$. When the tumour thickness exceeded $7 \mathrm{~mm}$, the cervical metastasis rate increased to $44 \%$ (4/9). The difference in metastasis for 7-mm tumour thickness is significant with $p=0.03$.

Within the group of floor of mouth carcinomas $(n=15)$, none of the patients had cervical metastasis with histological tumour thickness of $7 \mathrm{~mm}$ or less. When the tumour thickness exceeded $7 \mathrm{~mm}$, the cervical metastasis rate increased to $80 \%(4 / 5)$. The difference in metastasis for 7-mm tumour thickness is significant at $p=0.001$.

Local recurrence versus tumour thickness

Tumour thickness measured by histopathology was used for correlation with local recurrences. In our series, 12 patients $(12 / 65=19 \%)$ had a local recurrence within the follow-up period. In five cases, recurrences occurred at a thickness of $0-4 \mathrm{~mm}(5 / 20=25 \%)$, none in the $4-7-\mathrm{mm}$ group, two in the $7-10-\mathrm{mm}$ group $(2 / 7=22 \%)$ and no local recurrence occurred in the group with tumour thickness of $>9 \mathrm{~mm}$. 
Table 2 Sensitivity, specificity and significance level versus cut-off points for tumour thickness

\begin{tabular}{llll}
\hline Cut-off point & Sensitivity & Specificity & $p$ value \\
\hline Total group $(n=56)$ & & & \\
$\geq 3 \mathrm{~mm} /<3 \mathrm{~mm}$ & $90 \%$ & $26 \%$ & 0.275 \\
$\geq 4 \mathrm{~mm} /<4 \mathrm{~mm}$ & $95 \%$ & $33 \%$ & 0.016 \\
$\geq 5 \mathrm{~mm} /<5 \mathrm{~mm}$ & $88 \%$ & $39 \%$ & 0.019 \\
$\geq 6 \mathrm{~mm} /<6 \mathrm{~mm}$ & $90 \%$ & $53 \%$ & 0.001 \\
$\geq 7 \mathrm{~mm} /<7 \mathrm{~mm}$ & $88 \%$ & $64 \%$ & 0.001 \\
$\geq 8 \mathrm{~mm} /<8 \mathrm{~mm}$ & $87 \%$ & $21 \%$ & $<0.001$ \\
Tongue carcinomas $(n=36)$ & & $26 \%$ & \\
$\geq 3 \mathrm{~mm} /<3 \mathrm{~mm}$ & $100 \%$ & $29 \%$ & \\
$\geq 4 \mathrm{~mm} /<4 \mathrm{~mm}$ & $100 \%$ & $42 \%$ & \\
$\geq 5 \mathrm{~mm} /<5 \mathrm{~mm}$ & $89 \%$ & $44 \%$ & \\
$\geq 6 \mathrm{~mm} /<6 \mathrm{~mm}$ & $92 \%$ & $43 \%$ & \\
$\geq 7 \mathrm{~mm} /<7 \mathrm{~mm}$ & $89 \%$ & & \\
$\geq 8 \mathrm{~mm} /<8 \mathrm{~mm}$ & $86 \%$ & $40 \%$ & \\
Floor of mouth carcinomas $(n=15)$ & & $50 \%$ & 0.153 \\
$\geq 3 \mathrm{~mm} /<3 \mathrm{~mm}$ & $100 \%$ & $67 \%$ & 0.017 \\
$\geq 4 \mathrm{~mm} /<4 \mathrm{~mm}$ & $100 \%$ & $80 \%$ & 0.029 \\
$\geq 5 \mathrm{~mm} /<5 \mathrm{~mm}$ & $100 \%$ & $80 \%$ & 0.081 \\
$\geq 6 \mathrm{~mm} /<6 \mathrm{~mm}$ & $100 \%$ & $100 \%$ & 0.099 \\
$\geq 7 \mathrm{~mm} /<7 \mathrm{~mm}$ & $100 \%$ & 0.029 \\
$\geq 8 \mathrm{~mm} /<8 \mathrm{~mm}$ & $100 \%$ & 0.004 \\
\hline
\end{tabular}

There was no significant correlation between chance of local recurrence and tumour thickness.

\section{Discussion}

Synopsis of key/new findings

Although this is a retrospective study, all measurements were performed only once and by the same observer, and histology was not available in all patients, this study demonstrates that the measurement of tumour thickness with the new generation of intra-oral US transducers correlates well with histopathological thickness in oral cavity cancer $(R=0.93)$. Between 2004 and 2007, we used a non-dedicated small-parts transducer for measurement and this yielded inferior results $(R=0.05)$. This clearly shows that it is necessary to use a dedicated small-parts transducer to obtain reliable measurements.

In our study, MRI correlated less well with histopathology than US $(R=0.54)$. Worldwide, MRI measurements are regularly performed in patients with oral cancer. In our series, 13 of the 36 patients had lesions that could not be measured by MRI because of superficial growth, and these were treated with PDT. Therefore, histopathological measurement could not be performed. We were able to perform correlation in 26 cases; in those cases whereboth MRI and histopathological measurements were available, the correlation was only $R=0.54$.

In this study, the risk of metastasis in the neck with tumour thickness of $6 \mathrm{~mm}$ or less was 12\% (five out of 42), whereas when tumour thickness was $7 \mathrm{~mm}$ or more this risk was $57 \%$ (eight out of 14). For tongue carcinoma, the risk of metastasis in the neck with tumour thickness of $6 \mathrm{~mm}$ or less was $11 \%$ (three out of 27), whereas when tumour thickness was $7 \mathrm{~mm}$ or more this risk was $44 \%$ (four out of nine). For floor of mouth carcinoma, the risk of metastasis in the neck with tumour thickness of $6 \mathrm{~mm}$ or less was $0 \%$ (none out of ten), whereas when tumour thickness was $7 \mathrm{~mm}$ or more this risk was $80 \%$ (four out of five). From these data we conclude that within the overall group 7-mm tumour thickness is the cut-off value that optimally stratifies patients at a low versus high risk of development of neck node metastases $(p=0.001)$. However, as shown in Table 2, it is a matter of compromise between the sensitivity and specificity of a given cut-off value to make a choice for the optimal value. With a cut-off point of $7 \mathrm{~mm}$, the sensitivity in our study was $88 \%$ and the specificity $57 \%$ (Table 2 ). By dividing the group by site, the optimal cut-off value would be $7 \mathrm{~mm}$ for both groups, although this was determined within small groups $(n=36$ vs $n=15)$.

\section{Comparisons with other studies}

Our findings, using the dedicated intra-oral/intra-operative probe confirm those published by Iro and Nitsche [12]. Rasgon et al. [3] showed that the percentage of cervical lymph node metastases in lesions less than 5-mm thick was significantly lower compared with those with lesions with a thickness more than $5 \mathrm{~mm}$. Also, Shintani et al. [10], who studied 24 patients, found a strong correlation between tumour thickness measured with US and histology (Pearson's product $R=0.98$ ). They found that tumours thicker than $20 \mathrm{~mm}$ showed discordant results, possibly caused by tissue constriction during fixation with formalin. Lesions smaller than $10 \mathrm{~mm}$ showed a significantly better correlation.

Shintani et al. [10] also compared the accuracy of US and MRI in assessing tumour thickness. They found that US and MRI correlated well with histopathology. However, MRI could not identify most of the tumours less than $5.0-\mathrm{mm}$ 

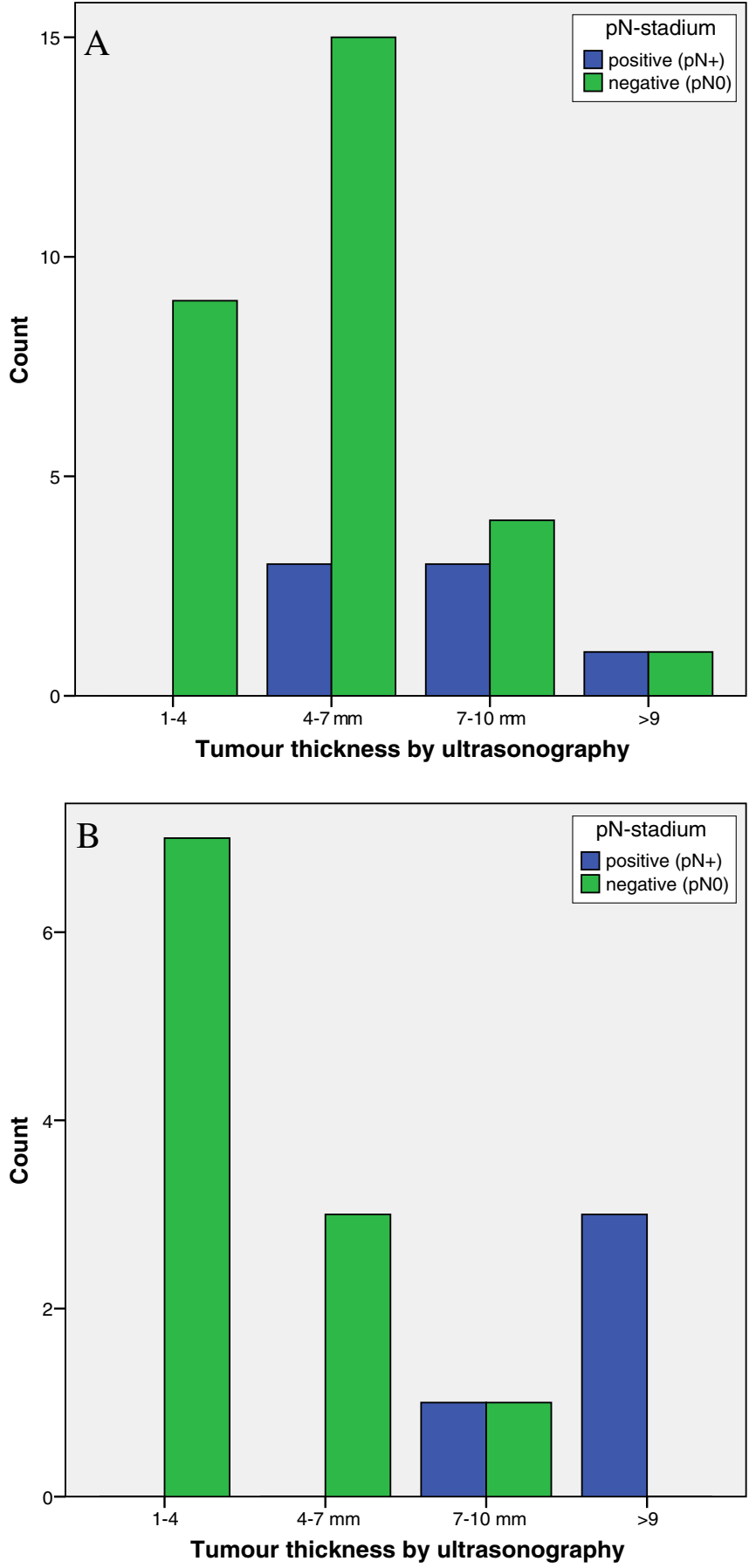

Fig. 6 Relationship between tumour thickness and cervical metastases divided by site. Tumour thickness measured by intra-oral US probe, if not available measured by histopathology. Green represents the patients with no neck metastasis within the 2-year follow-up period; blue represents the patients with positive neck nodes during the follow-up period. a The group with tongue carcinoma $(n=36)$; $\mathbf{b}$ the group with floor of mouth carcinoma $(n=15)$

thick. Preda et al. [11] showed a significant direct correlation between the measured histological and measured MRI tumour thickness (correlation coefficient $=0.80, p<0.0001$ ).

In the literature, discussion remains as to which cut-off point is optimal $[1-4,10-30]$, and in the more recent literature, cut-off points range between 3 and $8 \mathrm{~mm}[2,13]$.
In a large clinical review by Pentenero et al. [4], tumour thickness was shown to be an important parameter for predicting nodal metastases and for survival. They showed that in the literature the cut-off thickness predicting neck metastasis and survival varied from $1.5 \mathrm{~mm}$ to $10 \mathrm{~mm}$. Thus, it remains difficult to choose a reliable cut-off point for elective neck treatment and/or adjuvant radiotherapy.

The indication for elective neck treatment is mainly based on the expected risk of occult metastases. With respect to this risk assessment, Spiro et al. [1] retrospectively analysed tumour thickness in 92 patients treated with surgery for tongue and floor of mouth carcinomas. They concluded that for clinically N0 oral cancer, elective neck dissection was indicated in patients with depth invasion of more than $2 \mathrm{~mm}$ because in these tumours the risk of metastases reached $40 \%$. Fukano et al. [13], on the other hand, showed that tongue tumours exceeding $5 \mathrm{~mm}$ carried a risk of $65 \%$ for neck metastases, whereas those infiltrating $5 \mathrm{~mm}$ or less had a risk of only $6 \%$ (significant difference, $p=0.0003$ ).

A meta-analysis by Huang et al. [2] showed an association between tumour thickness and cervical lymphnode involvement and they stated that the optimal cut-off point for tumour thickness is $4 \mathrm{~mm}$. For oral cavity tumours thicker than $4 \mathrm{~mm}$, prophylactic neck management should generally be recommended according to this study.

At present, little is known about the correlation between tumour thickness and local recurrences of oral cavity carcinomas. In our study, there was no significant difference in local recurrences using the cut-off point for tumour thickness of more or less than $7 \mathrm{~mm}$. Yuen et al. [6] showed in 2002 that tumour thickness is prognostic for both nodal and local recurrence in oral carcinomas. With a tumour thickness less than $3 \mathrm{~mm}, 0 \%$ had local recurrences and $8 \%$ had nodal metastases; tumour thickness of more than $3 \mathrm{~mm}$ and up to $9 \mathrm{~mm}$ had $44 \%$ subclinical nodal metastasis and $7 \%$ local recurrence; tumour thickness of more than $9 \mathrm{~mm}$ had 53\% subclinical nodal metastasis and 24\% local recurrence. In our series, not enough patients with tumour thickness of $10 \mathrm{~mm}$ or more were included to compare these results. Extracting the results from Spiro et al. [1], local recurrence occurred in $5 \%$ of the group of tumours with thickness $<2 \mathrm{~mm}(2 / 40), 9 \%$ (3/35) within the group 3-8 $\mathrm{mm}$ thick and 25\% (4/17) for the group with thickness $>9 \mathrm{~mm}$. Local recurrence occurred significantly more in the group with tumour thickness of more than $8 \mathrm{~mm}$, at $p=0.035$. Yet more factors like perineural invasion, radical operation, postoperative treatment and N-staging should also be considered in relation to local recurrence [6].

\section{Clinical applicability of the study}

From this and other studies, it is clear that state-of-the-art US has a high correlation with histopathological thickness $[10,12]$. US thus seems to be the optimal technique in patients with no limited mouth opening or base of tongue involvement. US measurement is more reliable than MRI for the measurement of tumour thickness, especially in superficial lesions. 
All currently available literature shows depth of invasion or tumour thickness measurements of the primary tumour, most often only in small groups. The identification of a cut-off with adequate utility for clinical decisionmaking requires large studies and independent validation. making with regard to management of the primary tumour and neck. Based upon our findings, a wait-and-see policy is only warranted in superficial lesions with tumour thickness less than $7 \mathrm{~mm}$, but only if regular follow-up using USguided aspiration of the neck is ensured [31, 32].

\section{Conclusion}

Tumour thickness is an important predictive marker for lymph node metastases. As such, it can help in decision-

Open Access This article is distributed under the terms of the Creative Commons Attribution Noncommercial License which permits any noncommercial use, distribution, and reproduction in any medium, provided the original author(s) and source are credited.

\section{References}

1. Spiro RH, Huvos AG, Wong GY, Spiro JD, Gnecco CA, Strong EW (1986) Predictive value of tumor thickness in squamous carcinomas confined to the tongue and floor of the mouth. Am J Surg 152:345-350

2. Huang SH, Hwang D, Lockwood G, Goldstein DP, O'Sullivan B (2009) Predictive value of tumor thickness for cervical lymph-node involvement in squamous cell carcinoma of the oral cavity. Cancer 115:1489-1497

3. Rasgon BM, Cruz RM, Hilsinger RL, Sawicki JE (1988) Relation of lymphnode metastasis to histopathologic appearance in oral cavity and oropharyngeal carcinoma: a case series and literature review. Laryngoscope 99:1103-1110

4. Pentenero M, Gandolfo S, Carrozzo M (2005) Importance of tumor thickness and depth of invasion in nodal involvement and prognosis of oral squamous cell carcinoma: a review of the literature. Head Neck 27:1080-1091

5. Brandwein-Gensler M, Teixeira MS, Lewis CM et al (2005) Oral squamous cell carcinoma: histologic risk assessment, but not margin status, is strongly predictive of local disease-free and overall survival. Am J Surg Pathol 29:167-178

6. Po Wing Yuen A, Lam KY, Lam LK et al (2002) Prognostic factors of clinically stage I and II oral tongue carcinoma-A comparative study of stage, thickness, shape, growth pattern, invasive front malignancy grading, Martinez-Gimeno score, and pathologic features. Head Neck 24:513-520

7. Roepman P, de Jager A, Groot Koerkamp MJ, Kummer A, Slootweg PJ, Holstege FC (2006) Maintenance of head and neck tumor gene expression profiles upon lymph node metastasis. Cancer Res 66:11110-11114
8. Biel MA (2007) Photodynamic therapy treatment of early oral and laryngeal cancers. Photochem Photobiol 83:10631068

9. Bier-Laning CM, Durazo-Arvizu R, Muzaffar K et al (2009) Primary tumor thickness as a risk factor for contralateral cervical metastases in $\mathrm{T} 1 /$ $\mathrm{T} 2$ oral tongue squamous cell carcinoma. Laryngoscope 119:883-888

10. Shintani S, Yoshihama Y, Ueyama Y et al (2001) The usefulness of intraoral ultrasonography in the evaluation of oral cancer. Int J Oral Maxillofac Surg 30:139-143

11. Preda L, Chiesa F, Calabrese L et al (2006) Relationship between histologic thickness of tongue carcinoma and thickness estimated from preoperative MRI. Eur Radiol 16:2242-2248

12. Iro H, Nitsche $N$ (1989) Intra-oral sonography in neoplasms of the mouth and base of the tongue. HNO 37:329332

13. Fukano H, Matsuura H, Hasegawa Y, Nakamura S (1997) Depth of invasion as a predictive factor for cervical lymph node metastasis in tongue carcinoma. Head Neck 19:205-210

14. Mohit-Tabatabai MA, Sobel H, Rush BF, Mashberg A (1986) Relation of thickness of floor of mouth stage I and II cancers to regional metastasis. Am J Surg 152:351-353

15. Woolgar JA, Scott J (1995) Prediction of cervical lymph node metastasis in squamous cell carcinoma of the tongue/ floor of mouth. Head Neck 17(6):463472

16. Martínez-Gimeno C, Rodriguez E, Vila CN, Varela CL (1995) Squamous cell carcinoma of the oral cavity: a clinicopathologic scoring system for evaluating risk of cervical lymph node metastasis. Laryngoscope 105:728-733

17. Byers RM, El Naggar A, Lee YY et al (1998) Can we detect or predict the presence of occult nodal metastases in patients with squamous carcinoma of the oral tongue? Head Neck 20:138144
18. Scheer M, Kubler A, Manawi NN, Reuther T, Zöller JE (2005) Endosonographic imaging of tumor thickness in oral squamous cell cancer and its effect on the incidence of lymph node metastases. Mund Kiefer Gesichtschir 9:282-289

19. Veness MJ, Morgan G, Sathiyaseelan Y, Gebski V (2005) Anterior tongue cancer and the incidence of cervical lymph node metastases with increasing tumour thickness: should elective treatment to the neck be standard practice in all patients? ANZ J Surg 75:101-105

20. Jing J, Li L, He W, Sun G (2006) Prognostic predictors of squamous cell carcinoma of the buccal mucosa with negative surgical margins. J Oral Maxillofac Surg 64:896-901

21. Clark JR, Naranjo N, Franklin JH, de Almeida J, Gullane PJ (2006) Prognostic variables in N0 oral carcinoma. Otolaryngol Head Neck Surg 135:748-753

22. Wallwork BD, Anderson S, Coman WB (2007) Squamous cell carcinoma of the floor of the mouth: tumour thickness and the rate of cervical metastasis. ANZ J Surg 77:761-764

23. Suzuki M, Suzuki T, Asai M et al (2007) Clinicopathological factors related to cervical lymph node metastasis in a patient with carcinoma of the oral floor. Acta Otolaryngol Suppl 559:129-135

24. Okura M, Iida S, Aikawa T et al (2008) Tumor thickness and paralingual distance of coronal MR imaging predicts cervical node metastases in oral tongue carcinoma. AJNR Am J Neuroradiol 29:45-50

25. Kim SY, Roh J, Kim JS et al (2008) Utility of FDG PET in patients with squamous cell carcinomas of the oral cavity. Eur J Surg Oncol 34:208-215 
26. El-Okeily M, El-Bouihi M, Ricard AS et al (2008) Mouth floor and mobile tongue epidermoid carcinomas thickness: prognostic value. Rev Stomatol Chir Maxillofac 109:81-85

27. Natori T, Koga M, Anegawa E et al (2008) Usefulness of intra-oral ultrasonography to predict neck metastasis in patients with tongue carcinoma. Oral Dis 14:591-599
28. Jones KR, Lodge-Rigal R, Reddick RL et al (1992) Prognostic factors in the recurrence of stage I and II squamous cell cancer of the oral cavity. Arch Otolaryngol Head Neck Surg 118:483485

29. Hosal AS, Unal O, Ayhan A (1998) Possible prognostic value of histopathologic parameters in patients with carcinoma of the oral tongue. Eur Arch Otorhinolaryngol 255:216-219

30. Nathanson A, Agren K, Biorklund A et al (1989) Evaluation of some prognostic factors in small squamous cell carcinoma of the mobile tongue: a multicentre study in Sweden. Head Neck 11:387-392
31. Van den Brekel MW, Stel HV, Castelijns JA, Croll GJ, Snow GB (1991) Lymph node staging in patients with clinically negative neck examinations by ufltrasound and ultrasound-guided aspiration cytology. Am J Surg 162:362-366

32. Van den Brekel MW (1996) US-guided fine-needle aspiration cytology of neck nodes in patients with N0 disease.

Radiology 201:580-581 